\title{
Epaxial Division of the Myotome
}

National Cancer Institute

\section{Source}

National Cancer Institute. Epaxial Division of the Myotome. NCI Thesaurus. Code C34163.

The small, dorsal division of the myotome. Myoblasts from this section form the extensor muscles of the neck, vertebral column, and lumbar region. 